\title{
HUBUNGAN PENGETAHUAN PREMENSTRUAL SYNDROM DENGAN UPAYA MENGATASI PREMENTRUAL SYNDROM PADA REMAJA PUTRI DI RW 1 DESA KLUNJUKAN, KECAMATAN SRAGI, KABUPATEN PEKALONGAN
}

\author{
Widyah Setiyowati' ${ }^{1)}$, Titik Kurniawati ${ }^{2}$, Mei Nursaroh ${ }^{3)}$ \\ 1,2,3) Akademi Kebidanan Abdi Husada Semarang \\ Jl. Kol. HR. Hadijanto no 70, Banaran, Gunungpati Semarang \\ Email: widyahsetiyowati @gmail.com
}

\begin{abstract}
ABSTRAK
Masalah kesehatan reproduksi merupakan masalah yang kompleks sehingga memerlukan penanganan secara intensif dan terkoordinasi baik secara lintas program, lintas sektor maupun lintas disiplin ilmu memperhatikan sosial budaya. Salah satunya adalah masalah reproduksi pada remaja. Menurut suatu penelitian, sekitar 40\% wanita berusia 14-50 tahun mengalami premenstrual syndrome. Dalam suatu penelitian terhadap 384 jiwa wanita yang berusia 15 tahun melaporkan bahwa mereka yang mengalami premenstrual syndrome sebanyak 14\%. Premenstrual syndrome (PMS) merupakan gangguan siklus yang umum terjadi pada wanita muda pertengahan, ditandai dengan gejala fisik dan emosional yang konsisten. Gejala dapat diperkirakan dan biasanya terjadi secara regular pada 7-14 hari sebelum menstruasi dan akan mengilang pada saat menstruasi. Pengetahuan remaja tentang perubahan yang terjadi secara fisik, kejiwaan, dan kematangan seksual akan memudahkan remaja untuk memahami serta mengatasi berbagai keadaan yang membingungkannya. Tujuan Penelitian ini untuk mengetahui hubungan pengetahuan premenstrual syndrom dengan upaya mengatasi premenstrual syndrom pada remaja putri di Desa Klunjukan RW 01, Kecamatan Sragi, Kabupaten Pekalongan. Penelitian ini termasuk penilitian bidang ilmu kebidanan dalam melaksanakan pelayanan kebidanan pada remaja. Jenis penelitian ini adalah penelitian survey dengan rancangan cross sectional. Populasi dalam penelitian ini adalah 36 remaja putri sedangkan sampel yang diambil dengan tehnik total sampling pada keseluruhan populasi. Data yang dikumpulkan dalam penelitian ini adalah data primer dengan kuesioner dan data sekunder. Tingkat pengetahuan remaja tentang premenstrual syndrome termasuk kategori cukup 63,9\%. perilaku mengatasi premenstrual syndrom termasuk dalam kategori tidak ada upaya sebanyak 94,4\%. Hasil analisis bivariat diperoleh hasil $p$ value sebesar 0,283, $(0,283>0,05)$, maka tidak ada hubungan yang bermakna antara pengetahuan premenstrual syndrome dengan upaya mengatasi premenstrual syndrome pada remaja putri di Desa Klunjukan RW 01, Kecamatan Sragi, Kabupaten pekalongan. Saran diberikan pada remaja putri agar meningkatkan pengetahuan dan upaya mengatasi premenstrual syndrom sehingga meningkatkan derajat kesehatan reproduksinya.
\end{abstract}

Kata Kunci: Pengetahuan, Upaya mengatasi premenstrual syndrom

\section{ABSTRACT}

The problem of reproductive health is a complex problem that requires intensive and coordinated handling both across programs, across sectors and across disciplines of social and cultural concern. One of them is reproductive problems in adolescents. According to one study, about 40\% of women aged 14-50 years experience premenstrual syndrome. In a study of 384 souls of women aged 15 years reported that those who experienced premenstrual syndrome were 14\%. Premenstrual syndrome (PMS) is a common cycle disorder in mid-young women, characterized by consistent physical and emotional symptoms. Symptoms can be expected and usually occur regularly on 7-14 days before menstruation and will disappear during menstruation. Adolescent knowledge about changes that occur physically, psychologically, and sexual maturity will make it easier for teens to understand and overcome various situations that confuse them. The purpose of this study was to determine the relationship of premenstrual syndromic knowledge with efforts to overcome premenstrual syndrome in adolescent girls in RW 1 Klunjukan Village, Sragi District, Pekalongan Regency. This research includes research in the field of midwifery in carrying out midwifery services for adolescents. This type of research is a survey research with cross sectional design. The population in this study was 36 young women while the sample taken with total sampling techniques in the whole population. Data collected in this study were primary data with questionnaires and secondary data. 
The level of knowledge of adolescents about premenstrual syndrome is quite 63.9\%. behavior to overcome premenstrual syndrome is included in the category of no effort as much as $94.4 \%$. The bivariate analysis results obtained $p$ value of 0.283, (0.283>0.05), so there is no meaningful relationship between premenstrual syndrome knowledge and efforts to overcome premenstrual syndrome in adolescent girls in the village of Klunjukan RW 01, Sragi District, Pekalongan Regency. Suggestions are given to young women to increase their knowledge and efforts to overcome premenstrual syndrome, thereby increasing the degree of reproductive health.

Keywords: Knowledge, Efforts to overcome premenstrual syndrome

\section{PENDAHULUAN}

Salah satu komponen kesehatan reproduksi yang dapat memberikan gambaran umum keadaan kesehatan reproduksi Indonesia adalah masalah reproduksi pada remaja. Masalah kesehatan reproduksi merupakan masalah yang kompleks sehingga memerlukan penanganan secara intensif dan terkoordinasi baik secara lintas program, lintas sektor maupun lintas disiplin ilmu memperhatikan sosial budaya.(Wiknjosastro, 2008).

Berdasarkan proyeksi Badan Perencanan Pembangunan Nasional (Bappenas) jumlah penduduk Indonesia pada tahun 2018 mencapai 256 juta jiwa. Jumlah tersebut terdiri dari 133,17 juta jiwa laki-laki dan 131,88 juta jiwa perempuan. Jumlah kelompok usia 10-19 tahun di Indonesia menurut Sensus Penduduk sebanyak 43,5 juta jiwa atau sekitar $18 \%$ dari jumlah penduduk.

Berdasarkan Badan Pusat Statistik Provinsi Jawa Tengah jumlah remaja pada tahun 2017 kelompok usia 10-14 tahun sekitar 8,3 juta jiwa. Jumlah tersebut terdiri dari 4,3 juta jiwa laki-laki dan 4 juta jiwa perempuan (Profil Kesehatan Jawa Tengah, 2017). Sedangkan di Kota Pekalongan menurut Badan Pusat Statistik Kota Pekalongan jumlah remaja pada tahun 2017 kelompok usia 10-14 tahun sekitar 82 ribu jiwa. Jumlah tersebut terdiri dari 43 ribu jiwa laki-laki dan 39 ribu jiwa perempuan. Kesehatan reproduksi adalah suatu keadaan sejahtera fisik, mental dan sosial secara utuh, tidak semata-mata bebas dari penyakit atau kecacatan dalam semua hal yang berkaitan dengan system reproduksi, serta fungsi dan proesnya (Widyastuti, 2009).

Premenstrual syndrome (PMS) merupakan gangguan siklus yang umum terjadi pada wanita muda pertengahan, ditandai dengan gejala fisik dan emosional yang konsisten. Gejala dapat diperkirakan dan biasanya terjadi secara regular pada 7-14 hari sebelum menstruasi dan akan mengilang pada saat menstruasi (Syiamti, 2011).
Menurut suatu penelitian, sekitar $40 \%$ wanita berusia 14-50 tahun mengalami premenstrual syndrome. Berdasarkan hasil survey tahun 1982 di Amerika Serikat menunjukkan premenstrual syndrome di alami oleh 50\% wanita dengan sosio-ekonomi menengah yang datang ke klinik ginekologi. Dalam suatu penelitian terhadap 384 jiwa wanita yang berusia 15 tahun melaporkan bahwa mereka yang mengalami premenstrual syndrome sebanyak 14\%. (Nurhayati, 2012). Pengetahuan tentang perubahan yang terjadi secara fisik, kejiwaan, dan kematangan seksual akan memudahkan remaja untuk memahami serta mengatasi berbagai keadaan yang membingungkannya. Setiap remaja wanita perlu informasi tentang haid serta tentang alat reproduksi wanita. Dengan melaksanakan berbagai metode untuk memberikan pengetahuan pada remaja, mengenai kesehatan reproduksi, diharapkan akan tumbuh keadaan yang kondusif dalam peningkatan pengetahuan dan sikap (Widiastuti, 2009).

Tujuan penelitian ini adalah untuk mengetahui hubungan pengetahuan premenstrual syndrom dengan upaya mengatasi premenstrual syndrom pada remaja putri di Desa Klunjukan RW 01, Kecamatan Sragi, Kabupaten Pekalongan.

Manfaat yang diharapkan dari penelitian ini adalah menambah wawasan masyarakat khususnya remaja putri tentang premenstrual syndrom dan upaya mengatasinya. Hasil penelitian ini diharapkan dapat menjadi masukan dalam memberikan pendidikan kesehatan khususnya pada remaja putri tentang gangguan kesehatan reproduksi khususnya premestrual syndrom terutama upaya untuk mengatasi hal tersebut

\section{METODE}

Penelitian ini menggunakan rancangan Cross Sectional yaitu pengukuran variabel independen dan variabel dependen dalam waktu yang bersamaan yaitu untuk mencari hubungan antara dua variabel, dimana dalam 
penelitian ini terdapat satu variabel independen (pengetahuan) dan satu variabel dependen (upaya mengatasi). Menurut sifat dasar penelitian, peneliti ini termasuk jenis peneliti survey yaitu penelitian menggunakan sample untuk mengambil kesimpulan pada populasi.

Populasi adalah keseluruhan objek penelitian atau objek yang diteliti (Notoatmodjo, 2010). Populasi yang akan diambil pada penelitian ini adalah 36 remaja putri di Desa Klunjukan Rw 01, Kecamatan Sragi, Kabupaten Pekalongan. Sampel yang digunakan dalam penelitian ini adalah keseluruhan populasi sebanyak 36 responden. Teknik sampling pada penelitian ini menggunakan teknik total sampling pada keseluruhan populasi, sehingga mendapatkan 36 responden (Notoatmodjo, 2005). Cara ini dilakukan apabila populasinya kecil. Istilah lainnya sampling jenuh adalah sensus, dengan semua anggota populasi dijadikan sampel (Hidayat, 2010).
Sumber data yang dikumpulkan adalah data primer dan data sekunder. Data primer dikumpulkan melalui kuesioner pada remaja putri meliputi tingkat pengetahuan tentang premenstrual syndrom dan perilaku dalam upaya mengatasi premenstrual syndrom. Data sekunder merupakan data yang dikumpulkan melalui instansi terkait meliputi data remaja.

Analisis yang digunakan adalah analis is univariat dan bivariat. Variabel yang dianalis is adalah pengetahuan tentang premenstrual syndrom dan perilaku dalam upaya mengatasi premenstrual syndrom. Uji statistik yang digunakan adalah chi square dengan nilai $\mathrm{p}$ ( signifikansi) $\leq 0,05$. (Hidayat, 2010)

\section{HASIL PENELITIAN}

A. Analisa Univariat 1. Pengetahuan

Tabel 1

Distribusi Pengetahuan Remaja Putri Tentang Premenstrual Syndrome

\begin{tabular}{ccc}
\hline Pengetahuan & f & $\%$ \\
\hline Baik & 5 & 13.9 \\
Cukup & 23 & 63.9 \\
Kurang & 8 & 22.2 \\
\hline Total & 36 & 100.0
\end{tabular}

Berdasakan tabel diatas pengetahuan remaja putri tentang premenstrual syndrome terbanyak pada kategori cukup sebesar $23(63.9 \%)$ responden. sedangkan paling sedikit pada kategori baik sebesar $5(13,9 \%)$ responden

2. 2. Perilaku upaya mengatasi premestrual syndrom

Tabel 2

Distribusi Upaya Mengatasi Premenstrual Syndrom.

\begin{tabular}{ccc}
\hline Upaya mengatasi & $\mathbf{f}$ & $\boldsymbol{\%}$ \\
\hline Ada upaya & 2 & 5.6 \\
Tidak ada upaya & 34 & 94.4 \\
\hline Total & 36 & 100.0 \\
\hline
\end{tabular}

Berdasarkan tabel diatas upaya remaja putri dalam mengatasi premenstrual syndrome terbanyak pada kategori tidak ada upaya mengatasi premenstrual syndrome sebesar 34 (94.4\%) responden sedangkan yang ada upaya.

B. B. Analisa Bivariat

Tabel 3

Hasil tabulasi silang dan pengujian hubungan antara pengetahuan tentang premenstrual syndrome dengan upaya mengatasi premenstrual syndrome pada remaja putri.

\begin{tabular}{cccccccc}
\hline \multicolumn{6}{c}{ Upaya } & & \\
& \multicolumn{1}{c}{ Ada } \\
upaya & Tidak ada upaya & \multicolumn{2}{c}{ Total } \\
\hline & $\mathrm{f}$ & $\%$ & $\mathrm{f}$ & $\%$ & $\mathrm{f}$ & $\%$ \\
\hline Baik & 1 & $2,8 \%$ & 4 & $11,1 \%$ & 5 & $13,9 \%$
\end{tabular}




\begin{tabular}{ccccccc} 
Cukup & 1 & $2,8 \%$ & 2 & $61,1 \%$ & 23 & $63,9 \%$ \\
Kurang & 0 & $0 \%$ & 8 & $22,2 \%$ & 8 & $22,2 \%$ \\
\hline \multirow{2}{*}{ Total } & 2 & $5,6 \%$ & 4 & $94,4 \%$ & 36 & $100 \%$ \\
\hline
\end{tabular}

Berdasarkan tabel diatas dari remaja putri yang memiliki pengetahuan baik sebesar $5(13,9 \%)$, ada upaya mengatasi premenstrual syndrome sebesar $1(2,8 \%)$ dan tidak ada upaya mengatasi premenstrual syndrome sebesar 4 $(11,1 \%)$. Kemudian dari remaja putri yang memiliki pengetahuan cukup sebesar 23 $(63,9 \%)$, ada upaya mengatasi premenstrual syndrome sebesar $1(2,8 \%)$ dan tidak ada upaya mengatasi premenstrual syndrome sebesar $22(61,1 \%)$. Dan dari remaja putri yang memiliki pengetahuan kurang sebesar 8 $(22,2 \%)$, ada upaya mengatasi premenstrual syndrome sebesar $0(0 \%)$ dan tidak ada upaya mengatasi premenstrual syndrome sebesar 8 $(22,2 \%)$.

Uji fisher exact yang dilakukan untuk mencari hubungan antara pengetahuan premenstrual syndrom dengan upaya mengatasi premenstrual syndrom pada remaja putri diperoleh hasil $p$ value sebesar 0,283, karena nilai $\mathrm{p}$ value lebih besar dari 0,05 $(0,283>0,05)$, sehingga Ho diterima dan $\mathrm{Ha}$ ditolak maka tidak ada hubungan antara pengetahuan premenstrual syndrome dengan upaya mengatasi premenstrual syndrome pada remaja putri di Desa Klunjukan RW 01, Kecamatan Sragi, Kabupaten Pekalongan

\section{PEMBAHASAN}

1. Pengetahuan tentang premenstrual syndrom pada remaja putri

Dari hasil penelitian yang telah dilakukan pada 36 responden remaja putri di Desa Klunjukan RW 01, Kecamatan Sragi, Kabupaten Pekalongan, menunjukkan remaja yang memiliki pengetahuan cukup sebanyak $23(23 \%)$ remaja putri. Hal ini memberikan gambaran bahwa remaja putri belum cukup banyak yang mengetahui premenstrual syndrome secara baik. Dengan demikian masih perlu ditingkatkan lagi pengetahuan mereka. Sehingga sesuai dengan pendapat Widyastuti (2009) pembekalan pengetahuan tentang perubahan yang terjadi secara fisik, kejiwaan dan kematangan seksual akan memudahkan remaja untuk memahami serta mengatasi berbagai keadaan yang membingungkannya. Informasi tentang haid dan mimpi basah, serta tentang alat reproduksi lakilaki dan wanita perlu diperoleh setiap remaja.

Menurut pendapat Notoatmodjo (2007), pengetahuan merupakan hasil "tahu" dan ini terjadi setelah orang melakukan penginderaan terhadap suatu objek tertentu. Sehingga perlu adanya informasi yang jelas dan sering dalam rangka agar adanya upaya mengatasi terjadinya premenstrual syndrome yang tidak dapat teratasi.

2. Perilaku remaja putri tentang upaya mengatasi premenstrual syndrom

Upaya remaja putri dalam penelitian ini termasuk dalam kategori tidak ada upaya yaitu sebanyak 34 (94,4\%). Dengan adanya upaya remaja putri yaitu hanya dengan meredakan kram perut menggunakan botol air panas dan minum tablet $\mathrm{Fe}$ untuk menghilangkan keluhan saat sebelum menstruasi. Hal ini berarti kecenderungan remaja putri untuk mengatasi keluhan sebelum menstruasi atau usaha terhadap pencegahan terjadinya premenstrual syndrome dilakukan dengan cara sebaik-baiknya masih perlu ditingkatkan. Menurut Widyastuti (2009) dengan melaksanakan berbagai metode untuk memberikan pengetahuan kepada remaja mengenai kesehatan reproduksi diharapkan akan tumbuh keadaan kondusif dalam peningkatan pengetahuan, kemudian sikap dan perilaku kehidupan seksual yang sehat dan bertanggungjawab pada remaja. Dengan memberikan informasi yang jelas tentang premenstrual syndrome kepada para remaja putri maka 
dapat meningkatkan pengetahuan sehingga diharapkan dapat terbentuk adanya upaya mengatasi premenstrual syndrome.

3. Hubungan pengetahuan pengetahuan premenstrual syndrom dengan upaya mengatasi premenstrual syndrom

Hasil penelitian ini menunjukkan bahwa tidak ada hubungan antara pengetahuan premenstrual syndrom dengan upaya mengatasi premenstrual syndrom pada remaja putri di Desa Klunjukan RW 01, Kecamatan Sragi, Kabupaten Pekalongan. Dalam penelitian pengetahuan dari informasi. Informasi yang di miliki para remaja putri tentang jenis keluhan premenstrual syndrome, penyebab, cara mengatasi dan diagnosa terjadinya premenstrual syndrom remaja putri yang memiliki pengetahuan kurang dalam hal tentang premenstrual syndrom akan cenderung tidak adanya upaya untuk mengatasi premenstrual syndrom karena dengan pengetahuan yang kurang tersebut remaja putri belum bisa terdorong dalam upaya mengatasi premenstrual syndrome. Bagi remaja putri yang memiliki pengetahuan yang baik akan ada upaya mengatasi terhadap premenstrual syndrome. Dalam hal ini tidak sesuai dengan pendapat Saryono (2009) memberikan konseling dan edukasi dengan meyakinkan seorang wanita lainnyapun ada yang memiliki keluhan yang sama ketika menstruasi adalah penting. Pencatatan siklus menstrasi secara teratur setiap bulannya dapat memberikan gambarang seorang wanita mengenai waktu terjadinya premenstrual syndrome. Hasil penelitian ini tidak sesuai dengan teori lawrence Green yang menyatakan bahwa perilaku seseorang dipengaruhi oleh pengetahuan (Notoadmodjo, 2012), tetapi dalam penelitian ini perilaku bisa dipengaruhi oleh faktor lain misalnya sikap, nilai atau lingkungan fisik. Faktor lain ini bisa menjadi masukan untuk penelitian selanjutnya.

\section{KESIMPULAN DAN SARAN}

A. Kesimpulan

1. Sebagian besar pengetahuan remaja putri tentang premenstrual syndrom di
Desa Klunjukan Rw 01, Kecamatan Sragi, Kabupaten Pekalongan dari 36 responden termasuk kategori cukup yaitu sebanyak 23 responden (63,9\%).

2. Sebagian besar upaya mengatasi premenstrual syndrom remaja putri di Desa Klunjukan Rw 01, Kecamatan Sragi, Kabupaten Pekalongan dari 36 responden termasuk kategori tidak ada upaya yaitu sebanyak 34 responden (94.4\%).

3. Tidak ada hubungan antara pengetahuan premenstrual syndrom dengan upaya mengatasi premenstrual syndrom pada remaja putri di Desa Klunjukan Rw 01, Kecamatan Sragi, Kabupaten Pekalongan dengan p value $0,283(0,283>0,05)$

B. Saran

1. Bagi Pemerintah (Dinas Kesehatan Kota Pekalongan)

Dapat meningkatkan dalam memberikan informasi dan konseling melalui pelaksanaan program kegiatan bimbingan dan pembinaan tentang kesehatan reproduksi terutama pengetahuan tentang premenstrual syndrom pada remaja putri di kota pekalongan.

2. Bagi Peneliti

Dapat menambah wawasan dan pengetahuan dalam meningkatkan ilmu terutama tentang premenstrual syndrom dan upaya mengatasi premenstrual syndrome.

3. Manfaat Aplikatif a. Bagi Remaja Putri

Diharapkan para remaja putri agar aktif mencari informasiinformasi tentang premenstrual syndrom di organisasi-organisasi kesehatan atau remaja serta pada tenaga kesehatan yang ada sehingga adanya pencegahan dan upaya mengatasi premenstrual syndrom dapat ditingkatkan.

b. Bagi Institusi Pendidikan

Dapat menambah hasil kepustakaan dan menambah wawasan pengetahuan bagi mahasiswi tentang premenstrual syndrome. 
c. Desa Klunjukan Rw 01, Kecamatan Sragi,

Kabupaten Pekalongan.

Dapat meningkatkan dalam memberikan informasi dan konseling melalui wadah organisasi misalnya karang taruna tentang premenstrual syndrom khususnya remaja putri di Desa Klunjukan Rw 01, Kecamatan Sragi, Kabupaten Pekalongan. Sehingga pengetahuan remaja putri yang cukup dan kurang mampu menjadi lebik baik.

4. Bagi Profesi Bidan

Dapat memberikan informasi lebih tentang pencegahan dan upaya mengatasi premenstrual syndrom dengan cara bekerja sama dengan puskesmas diwilayah setempat untuk mengadakan kunjungan ke organisasi-organisasi yang ada dan PKRR (Pendidikan Kesehatn Reproduksi Remaja) sehingga para remaja putri lebih mengetahui tentang premenstrual syndrome.

\section{DAFTAR PUSTAKA}

1. Arikunto, S. 2006. Prosedur penelitian Suatu Pendekatan Praktek. Rineka Cipta. Jakarta.

2. Badan Pusat Statistik Kota Pekalongan. 2018 Jumlah Penduduk Menurut Kelompok Umur dan Jenis Kelamin di Kota Pekalongan.

3. https//pekalongankota .bps.go.id/statictable/2018/01/16/268/j umlah-penduduk-menurut-umur-danjenis-ke lamin-di-provinsi-jawatengah-2015-2017.html di akses pada tanggal 20 Juni 2019

4. Badan Pusat Statistik Provinsi Jawa Tengah. 2018. Jumlah Penduduk Menurut Kelompok Umur dan Jenis Kelamin di Provinsi Jawa Tengah.https//jateng.bps.go.id/staticta ble/2017/10/26/1535/jumlahpenduduk-menurut-umur-dan-jeniskelamin-di-provinsi-jawa-tengah2015-2017.html di akses pada tanggal 20 Juni 2019

5. Burns et al, A. August. 2009. Memelihara Kesehatan Reproduksi Perempuan Sejak Dini. Yogyakarta: Insist Press
Habibah,

F.

2016.

http://repository.umy.ac.id/bitstream/h andle/

123456789/2433/BAB\% 201.pdf?sequ ence $=5 \&$ is Allowed $=y$ diakses pada tanggal 15 Juni 2019

7. Jatman, Darmanto. 2000. Psikologi Perkembangan. Semarang: Badan Penerbit Universitas Diponegoro

8. Mubarok. 2007. Promosi Kesehatan. Graha Ilmu: Yogyakarta

9. Nugroho, Taufan dan Ari Setiawan. 2010. Kesehatan Wanita, Gender dan Permasalahannya. Nuha Medika: Yogyakarta.

10. Notoatmodjo, S. 2007. Pendidikan dan Perilaku Kesehatan. Rineka Cipta: Jakarta.

11. Notoatmodjo, S. 2012. Metodologi Penelitian Kesehatan. Edisi Revisi. Rineka Cipta. Jakarta

12. Saryono, Waluyo Sejati. 2009. Sindrom Premenstruasi Mengungkap Tabir Sensitifitas

13. Perasaan Menjelang Menstruasi. Nuha Medika: Yogyakarta.

14. Siyamti, S. Pratiwi, Herdin. 2011. Hubungan Antara Tingkat Kecemasan Dengan Sindrom Premenstruasi Pada Mahasiswi Tingkat II Akademi Kebidanan Estu Utomo Boyolali.

15. Widyastuti. 2009. Kesehatan Reproduksi. Fitramaya: Yogyakarta.

16. Wiknjosastro. 2006. Ilmu Kandungan. Jakarta: Yayasan Bina Pustaka. 